\title{
Safety Management Enhancement: The Case of Mintra Academy
}

\author{
Frank Cairney \\ Mintra Training Portal Ltd, United Kingdom
}

\begin{abstract}
:
This paper aims to provide a reflective look on fostering a 'safety culture' environment by providing oil and gas industry professionals with an opportunity to gain a recognised qualification relevant to their daily work. On a practical scale, safety culture can be stimulated by Control of Work programmes, combining various elements of safety and risk management, human factor management, effective communication and safety leadership. The Mintra Academy takes safety-related training to a new level by making training more contextual and compliant with industry standards utilising the Scottish Credit and Qualification Framework.
\end{abstract}

Paper type: Case study

Keywords: Training, Oil and Gas industry, Safety Culture, Safety Management, Professional Development, SCQF, Control of Work 


\section{Introduction}

The inhospitable production environment of the North Sea, the hot and dusty deserts of the Middle East and the harsh climate in the frigid regions of Russia are simply geographical challenges faced by the global oil and gas industry. While other challenges, such as fluctuating oil price as well as competition from unconventional resources and renewables are equally serious and threatening; the BP Deepwater Horizon (Macondo) incident highlighted the importance of an unrelenting effort to establish high standards in safety management. The investigation by the National Oil Spill Commission (2011) reported a number of operational and managerial decisions which contributed to the tragedy, implying that behavioural and organisational factors were the main aspects leading to the disaster. For instance, many academic studies and industry reports on offshore accidents found that human factors contribute to the failure of evacuation (Musharraf et al., 2013; National Oil Spill Commission, 2011; Woodcock and $\mathrm{Au}, 2013)$. A successful evacuation operation depends on comprehensive preparedness (Norazahar et al., 2014) and also adequate safety culture (Bye et al., 2015; Guldenmund, 2000). As the exploration and production of petroleum moves to deeper, more isolated and even hostile environments, safety management and training becomes more important than ever. In this paper, we look at Control of Work training as the cornerstone of robust safety management and its relevancy to the encouragement of safety culture.

\section{Safety culture}

Safety culture is a broad concept in gaining a better understanding of the industry norms and managerial practices that shape beliefs and activities relating to safety (Guldenmund, 2000). Academic researchers and industry specialists have been investigating perceptions and attitudes of petroleum professionals towards evaluating risks (Mearns et al., 2004) and the influence of safety culture on the behaviours of offshore workers (Bye et al., 2015; Mearns et al., 2010). For example, based on a survey of 622 offshore workers, Mearns et al. (2004) found that the workers seemed to perceive that safety issues are sometimes secondary to production goals. Whilst the study did not indicate the level of workers' satisfaction with their respective employers, it was however noted that it's highly unlikely that the workers are fully committed to stay with their companies if no ongoing transferable skills training is provided, whereas investing in health and safety is associated with committed workforce as well as promotion of safety climate (Mearns et al., 2010). Moreover, promoting a 'health, safety and environment (HSE) culture' is a regulatory requirement for petroleum companies operating on the Norwegian Continental Shelf. Bye et al. (2015) concluded that the use of the term 'poor safety culture' to explain extensive non-compliance in investigation reports may have stimulated the regulated petroleum companies to enhance compliance and prioritise strategies in order to improve health and safety. Putting these together, we can suggest that safety culture is not just a term to describe organisational beliefs and employees attitudes towards safety; rather, it is also the efforts displayed by a company to promote a safe health and safe environment for its employees.

To create a stable safety-centred environment, operators need to take sufficient precautions interrelated with anticipated emergency responses, especially in terms of

International Journal of Management and Applied Research, 2015, Vol. 2, No. 3 
personnel competences and operational activities. This is what Mintra Training Portal Ltd aims to achieve -expanding personnel's knowledge on the subject of Control of Work (CoW) and, more importantly, introducing a more generic approach in CoW learnings that aims to cross the barriers previously created within the oil and gas industry by operators working within silos and individually running training to their own standards of CoW procedures. Additionally, Mintra recognises the importance of providing individuals with an opportunity to gain a recognised qualification relevant to their daily work, subsequently raising the credibility and importance of $\mathrm{CoW}$ training.

\section{The Control of Work programme}

The CoW programme is comprised of nine modules: general principles of Permit-ToWork Systems (HSG250), understanding safety cases, risk management, human factor management, effective communication, gas testing, safety leadership, planning and, last but not least, safe isolation. Modules are designed to introduce learnings to candidates through the use of eLearning packages as well as workshops, creating a blended learning approach. These modules are designed specifically for experienced offshore workers, team leaders, specialists and supervisors but could also be utilised for the learnings of Energy post-graduates to enhance their academic learnings. Some modules are mandatory and the combination of modules depends on the employee's position and experience. For instance, a supervisor who enrolled in a Work Responsible Supervisor Programme is required to complete eight modules, whereas an offshore worker enrolled in a Work Team Member Programme is required to complete four modules. Each programme has an associated qualification that will lead to an award accredited by the Scottish Credit and Qualification Framework (SCQF).Providing training configured in such a way that it ensures employees will achieve a well-rounded, academically recognised and best practice based knowledge, focused on their current role's requirements is key to improving safety management.

\section{Conclusion}

The offshore oil and gas exploration is associated with an increasing number of risks related to safety of operations due to technological complexity of extractive processes and associated maintenance. Not paying sufficient attention to safety management may lead to major safety and security incidents. The overall situation gets even more complex because of increased intensity in maritime activities in crowded littoral sea areas as well as from both manmade and natural hazards (Cordner, 2011). Moreover, different categories of employees may have different attitudes towards safety management and safety culture overall. While management executives recognise the safety system as a fundamental tool for safe conduct, the attitude among the workers differs, as it seems that they think they are able perform their duties properly without safety management system (Wold and Laumann, 2015). Altogether, an effective implementation of safety culture might be a challenging, longitudinal task.

The solution introduced by Mintra Academy can be seen as an inclusive approach, as it combines an effective application of academic theory to the practicalities of daily operations encountered by oil and gas industry professionals and executives. In addition, learning on SCQF credited courses will enhance recognition from industry

International Journal of Management and Applied Research, 2015, Vol. 2, No. 3 
as well as international academic institutions, thereby increasing the value of these courses to both the individual and industry organisations.

\section{References}

1. Bye, R. J., Rosness, R., and Røyrvik, J. D. (2015), "Culture' as a tool and stumbling block for learning: The function of 'culture' in communications from regulatory authorities in the Norwegian petroleum sector", Safety Science, https://doi.org/10.1016/j.ssci.2015.02.015

2. Cordner, L. (2011), "Managing Regional Risk: Offshore Oil and Gas Safety and Security in the Asia-Pacific Region", Australian Journal Of Maritime And Ocean Affairs, Vol. 3, No. 1, pp. 15-24.

3. Guldenmund, F. (2000) "The Nature of Safety Culture: A Review of Theory and Research", Safety Science, Vol. 34, No. 1-3, pp. 215-257.

https://doi.org/10.1016/S0925-7535(00)00014-X

4. Mearns, K., Rundmo, T., Gordon, R. and Fleming, M. (2004), "Evaluation of psychosocial and organizational factors in offshore safety: a comparative study", Journal Of Risk Research, Vol. 7, No. 5, pp. 545-561. https://doi.org/10.1080/1366987042000146193

5. Mearns, K.; Hope, L.; Ford, M. Tetrick, L. (2010), "Investment in workforce health: Exploring the implications for workforce safety climate and commitment", Accident Analysis \& Prevention, Vol. 42, No. 5, pp. 1445-1454. https://doi.org/10.1016/j.aap.2009.08.009.

6. Musharraf, M.; Hassan, J.; Khan, F.; Veitch, B.; MacKinnon, S. and Imitiaz, S. (2013), "Human reliability assessment during offshore emergency conditions", Safety Science, Vol. 59, pp. 19-27. https://doi.org/10.1016/j.ssci.2013.04.001

7. Norazahar, N.; Khan, F.; Veitch, B. and MacKinnon, S. (2014), "Human and organizational factors assessment of the evacuation operation of BP Deepwater Horizon accident", Safety Science, Vol. 70, pp. 41-49. https://doi.org/10.1016/j.ssci.2014.05.002

8. National Oil Spill Commission (2011), Deep Water: The Gulf Oil Disaster and the Future of Offshore Drilling, Washington, DC: National Commission on the BP Deepwater Horizon Oil Spill and Offshore Drilling.

9. Wold, T. and Laumann, K. (2015), "Safety Management Systems as communication in an oil and gas producing company", Safety Science, 72, pp. 2330. https://doi.org/10.1016/j.ssci.2014.08.004

10. Woodcock, B. and Au Z. (2013), "Human factors issues in the management of emergency response at high hazard installations", Journal of Loss Prevention in the Process Industries, Vol. 26 No. 3, pp. 547-557.

https://doi.org/10.1016/j.jlp.2012.07.002

International Journal of Management and Applied Research, 2015, Vol. 2, No. 3 